\title{
Binge-Watching: Video-on-Demand, Quality TV and Mainstreaming Fandom
}

\section{Abstract:}

This article explores the concept of the binge as viewing protocol associated with fan practices, industry practice and linked to 'cult' and 'quality' serialised content. Viewing binge-watching as an intersection of discourses of industry, audience and text, the concept is analysed here as shaped by a range of issues that dominate the contemporary media landscape. In this, factors like technological developments, fan discourses and practices being adopted as 'mainstream' media practice, changes in the discursive construction of 'television' and an emerging Videoon-Demand industry contribute to the construction of binge-watching as deliberate, selfscheduled alternative to 'watching TV'.

\section{Keywords:}

Binge-watching, Quality TV, Cult TV, Fan Studies, Video-on-Demand, DVD, Discourse Analysis, Television, Audience, Television Industry

This article explores the concept of binge-watching when applied to the consumption of serialised content on DVD or Video-on-Demand (VOD). Binge-watching reaches beyond assumed or actual viewing behaviour, but has implications for how VOD providers like Netflix or Amazon position themselves as an alternative to scheduled, synchronised and 'traditional' television. As a practice previously associated with the commodity of a DVD box set, 'bingeworthy' texts tend to be invested with some features of 'quality' or 'cult' that justify the extra 
expense of buying the DVDs or the VOD subscription. This is suggested by the vast amounts of lists of 'binge-worthy' texts on websites like imdb.com or cnn.com with titles ranging from the British Sherlock (BBC, 2010- ) or Peep Show (Channel 4, 2003- ) to knowingly camp soaps like Revenge (ABC, 2011- ) or Scandal (ABC, 2012- ) to comedies like New Girl (Fox, 2011) or Girls (HBO, 2012- ) to HBO dramas True Detective (HBO, 2014- ), The Newsroom (HBO, 2012- ) or Game of Thrones (HBO, 2011- ). ${ }^{1}$ Theoretically, any text can be binge-watched, but these lists do specify serialised content, often explicitly mentioning Netflix as a means to watch it. And they do not focus on supposedly 'low-culture' reality formats, but texts that feature award-winning actresses like Madeline Stowe or have been nominated for prestige awards. Charlotte Brunsdon links the rise of bingeing DVD box sets with a shift in the perception of television:

This new, good television, in contrast to old, bad, addictive television is not broadcast network television, but television which one either pays to see, or watches on DVD. Instead of being associated with housebound women, this new television is young, smart, and on the move, downloaded or purchased to watch at will. $(2010,65)$

As discussed in more detail later on, these texts are invested with more cultural acclaim than traditionally afforded to television texts. But they also encourage focussed, and self-scheduled binge-watching through complex narrative structures. Autonomous scheduling, as made possible through VHS, DVR, DVD or VOD, allows viewers to set aside time for the focussed and planned watching of content. As this suggests, the concept of binge-watching is understood here as discursive formation or an intersection of a variety of discourses. This study focusses on discourses of industry, text, and audience, though the latter point focusses on the figure of the fan and the mainstreaming of fandom rather than empirical audience research. 
Binge-watching serves the interests of the emerging Video-on-Demand (VOD) industry. Particularly the producers and distributors of original content, Netflix, Amazon and, in the US market, Hulu, have been exploring the 'binge model' as a way to publish content and bind customers. The article discusses 'cult' and 'quality' texts as encouraging and rewarding bingewatching through textual strategies. Yet, as mentioned above, supposedly 'bingeable’ texts also legitimise the viewing practice and, thus, the medium: if viewers stand to earn valued cultural capital, it is socially acceptable to binge, rather than watch several hours of scheduled television.

The deliberate, focussed attention payed to these texts can be associated with fan behaviour. Because of these links, fan studies is used here as an approach to conceptualise binge-watching. Yet, a viewing protocol loosely associated with fan discourses can only ever be understood as one part of a broad discursive formation of what constitutes a fan. Fan studies is used here as an approach to understand the somehow excessive audience-text relationship implied in the term binge, but it is not suggested that binge-watching and fandom automatically go hand in hand. Matt Hills (2013, 138), in an article on fan textual productivity, draws on Mirko Tobias Schäfer's concept of implicit and explicit participation. Hills argues that sending a tweet or updating one's profile or cover picture on facebook to reflect a fandom - for example an image of Walter White (Bryan Cranston) from Breaking Bad (AMC, 2008-13) or Peggy Olsen (Elisabeth Moss) from Mad Men (AMC, 2007- ) - can be counted as implicit textual productivity as it involves little effort. Binge-watching is no textual productivity, but a mode of consumption. Yet, it works to enable close textual analysis and the kind of implicit textual production viewers who are uncomfortable with the fan label may engage with (detailed textual analysis, tweeting, status updates, etc.) as confidently as fans might. Fan studies is used here to conceptualise potentially non-fan behaviour rather than explore fandom. As paradoxical as 
this seems, fan studies is a discipline that routinely deals with close audience-text relationships, something difficult to conceptualise outside of fandom.

The concept of the binge is analysed here via the three axes of industry-text-audience. Other axes, like technology or the discursive construction of what we mean by 'television', are touched upon, but not discussed in detail. The first step of this analysis will deal with issues of what constitutes a binge, how the term is of use for the industry and how the concept is used to promote the medium and publish content. In a second step, this article will look at what texts are 'bingeable' or 'binge-worthy' and in what ways they serve as sites of cultural value. The third part will access the binge via fan studies in order to conceptualise a close audience-text relationship.

\section{The VOD industry and the 'Binge-Model'}

The first question to ask is what we mean by the term binge-watching. In contexts such as binge drinking or binge eating, the term binge connotes self-harming behaviour, even associated with diseases like alcoholism and bulimia. A binge is excessive behaviour that deviates from the norm:

... to 'binge' suggests some form of shameful indulgence, and a lack of control. The widespread use of the term to describe a television viewing practice consequently implies a vague distaste for the medium itself. We do not, after all, refer to 'binge listening', when someone works his or her way through an entire symphony or a band's oeuvre. Nor do we call reading an entire novel in one sitting a 'binge'. A book that you can't 'put 
down', or a 'page turner' seems to have a higher cultural currency than the 'must watch’ television that leads to ‘binge’ viewing. (Ramsay 2013)

Yet, the term binge-watching is usually applied to media that are not TV, at least not in a 'traditional' sense: as Debra Ramsay argues herself, it is not watching consecutive hours of scheduled television the term is applied to, but watching, for example, a whole season of a series in one day, presumably on DVD. As Michael Z. Newman argues:

The new technological ensembles for television distribution and consumption have been seen as sources of liberation and legitimation. This is framed against television’s network-era history as a mass medium characterized by limited choices of 'least objectionable programming.' By contrast with its earlier status, TV in the convergence era has seen significant improvement in its place on the cultural hierarchy. (2014, 93)

In fact, the concept of binge-watching seems to have come up with the 'rise' of the DVD box set. As Amanda Lotz points out:

In the early 2000s, the success of full seasons of shows packaged on DVD surprised many in the industry. By 2005, DVD sales of television shows reached \$2.6 billion and accounted for nearly 20 percent of the overall DVD sales market [in the US]. (2014, location 3276)

Thus, the concept of binge-watching seems linked to a rise in DVD sales of serialised content. It may be mere speculation to suggest that DVD box sets are automatically binge-watched, but as discussed later, a binge is largely defined by being autonomously scheduled and only excessive relative to a norm that is difficult to pin down. 
The numbers of episodes watched to constitute a binge diverge significantly and often seem more like subjective estimates in relation to one’s own media consumption. Ramsay regards a day she spent watching an entire season of Supernatural (CW, 2005- ) as excessive. In a study by Harris Interactive, conducted of behalf of Netflix, the company summarised: “A majority (73\%) defined binge watching as watching between 2-6 episodes of the same TV show in one sitting” (2013). Yet, as The Atlantic journalist Nolan Feeney points out when discussing the Harris Interactive study:

... the minimum number of episodes did not distinguish between hourlong dramas and shorter sitcoms. By this definition, I could watch two episodes of 30 Rock [NBC, 2006-13] in a row and call that a binge-even though that's less than half the time it takes to watch a typical movie. (2014)

In his up-beat piece, Feeney then goes on to argue for a definition of a binge as roughly four episodes of drama. One important aspect he describes is the idea of excess, what Ramsay calls 'shameful indulgence'. Lisa Glebatis Perks conducted a study on what she calls media marathoning and finds that those marathoners who experience guilt usually do so because of their diminished social interaction while bingeing, guilt about 'wasted time' or regret because “readers did not have time to reflect on their stories and reading practices” (2015, location 2173). To capture this experience described as guilt, shame or regret, the term excess is used here to account for the idea that the amount of episodes watched exceed a 'norm', though this is not necessarily experienced as negative. The numbers given here diverge between two episodes and watching a whole season (for an American network series like Supernatural, roughly 20-24 episodes) of one serialised text in one day. Such a vast difference in numbers of episodes watched is easily explained: to determine excess, there needs to be a 'norm'. But considering that any definition of binge-watching is dependent on highly individualised 
viewing behaviour, common ground is hard to find. Scheduled television might give some idea on what we may consider a norm. The 'ration' of one new episode of a prime time series per week may be considered a norm for watching one series. Binge-watching two episodes of a series per day, thus, can be viewed as 'excess' when compared to the 'norm' of one episode per week on scheduled television. In this case, watching a whole season in one day seems particularly excessive. But Glebatis Perks finds that such behaviour is not unusual as many of her study subjects would schedule their marathons or binges,

...into breaks from school, work or programming schedules (e.g. when new television episodes go on hiatus during the winter holidays and summer). These media-rich floating holidays represent an escape from mundane routines and media habits. (2015, location 5021)

As such, the 'norm' and 'excess' are difficult to pin down, but what can be established is that the excess of a binge exceeds the 'ration' scheduled television offers by far. Furthermore, a binge suggests the consecutive watching of several episodes of one series, uninterrupted by the flow of television, which includes advertising breaks and a variety of programmes. This implies an intense - or ‘excessively’ close - relationship with a text. It highlights that binge-watching is decidedly different from following television flow where more than one programme is watched. In the case of DVD box sets, an important factor in determining excess may also be anticipation and monetary value of the commodity in relation to the time needed to consume it. In other words, considering that viewers often wait a long time for the release of a season on DVD and often pay a high price, watching the whole box set in only one or two sittings might also contribute to a subjective feeling of excess. Waiting periods remain with VOD, but the financial expense is significantly lower (if one doesn't count delivery systems such as computers or a broadband connection). What remains is the necessity to self-schedule, which may very well involve the excess of binge-watching. But a key factor is that the viewing is 
autonomously scheduled: control over one's own viewing behaviour is only possible because control over scheduling, traditionally in the hands of the broadcaster, is given to the viewer. Thus, binge-watching suggests an entirely different media experience than 'traditional', scheduled television can offer.

VOD, and particularly Netflix, builds on developments of the television landscape of the late 1990s and early 2000s where HBO, in particular, positioned itself as setting ‘quality’ standards. Unlike HBO, VOD cuts out the period audiences have to wait until a season of a TV series has been shown in weekly episodes and is published on DVD so that they can self-schedule and binge-watch. Netflix is a monthly subscription service, meaning that its main goal is to keep customers from cancelling subscriptions. Key to this are personalised recommendations to offer viewers more available content. But binge-watching is also part of this strategy: if Netflix can offer content that keeps viewers interested for long periods, for example catching up on four seasons of The Good Wife (CBS, 2009- ), it becomes less likely that they will cancel subscriptions as long as they are still bingeing. Thus, binge-watching is a crucial business strategy for Netflix. Offering a number as low as two episodes as an 'official’ minimum number for a binge might work in Netflix' business interests: the fewer episodes viewers have to watch to take part in the cultural 'trend' of bingeing the longer they will remain customers. It may hardly be surprising that other VOD services like HuluPlus and Amazon have adapted the same strategy in pushing original programming. While Hulu’s Farmed and Dangerous (Hulu, 2013) was still published in weekly episodes, only a few months later Deadbeat (Hulu, 2014- ) was put online as a complete season. Amazon followed a different strategy with Alpha House (Amazon, 2013- ). As David Carr notes in November 2013 in The New York Times: 
The first three episodes will be available on Nov. 15, free to all Amazon customers, and additional episodes will then be available to subscribers of Amazon Prime every week.

Lest you think Amazon is simply being generous, it is important to note that Prime members reportedly spend 150 percent more on the site after joining. You get the drift: Come for “Alpha House” and stick around to buy a big new flat-screen to watch it on. (2013)

Time Magazine also notes potential risks for Amazon and other relatively new VOD companies associated with Netflix’ strategy:

Amazon hopes that the release schedule will fuel more social media chatter for the shows. Some have criticized the Netflix model of releasing an entire season of its original series — like House of Cards [Netflix, 2013- ], Orange Is the New Black [Netflix, 2013- ] and Hemlock Grove [Netflix, 2013- ] — because conversations on Facebook and Twitter about episodes of the show (which can promote the show and earn more viewers) are difficult while everyone watches at a different pace. Some Netflix investors also worried it could encourage customers to bingewatch a season and then cancel their subscription — though the company said its initial experience with House of Cards showed that to be rare. (2013)

Yet, less than a year later, in July 2014, Laura Prudom reports in Variety that Transparent (Amazon, 2014- ) would be published using 'the binge model' on Amazon Prime later that year. Thus, Netflix' model, which combines the 'binge model' with personalised recommendations, a characteristic that has long been part of Amazon (though usually applied 
to other commodities), has transcended Netflix as a default model to publish new original content on VOD.

Partially, this needs to be viewed as a consequence of Netflix’ history as online-based DVD rental store. In the years when television drama became increasingly complex and led to the rise of the DVD box set, most DVD rental stores offered DVD box sets of TV series. When Netflix introduced the streaming option in the US in 2007, it seemed to follow that this included serialised drama, at least where the streaming rights could be negotiated. The publicity involving Netflix' production of a fourth season of Arrested Development (Fox, 2003-6, Netflix, 2013) certainly drove home the point that the 'binge model' as a way to publish content followed on seamlessly from the preceding trend to watch DVD box sets of entire seasons rather than episodes as scheduled by 'traditional' television:

...until 2012, viewers made the personal choice to defer viewing until they could amass a stock that would permit favored pacing [in the form of DVD box sets or illegal downloads] - distributors still released content in weekly intervals of individual episodes. Once it ventured into content creation, Netflix defied the model of weekly episode release and made available all of the episodes of the first 'season' of its original series Lilyhammer [Netflix, 2012- ] simultaneously, a strategy reproduced with much greater notice when releasing House of Cards in February 2013. Netflix suggested a possible future in which viewers would not have to wait for a linear, weekly delivery of content. (Lotz 2014, location 1774)

Netflix' viewing numbers are not public and the deliberation implied in binge-watching makes such measuring difficult. The severe losses Netflix stock took when the publication of the fourth season of Arrested Development did not immediately meet expectations in numbers of 
new subscribers indicates that Netflix, Hulu or Amazon stock is likely to react sensitively when viewing numbers are not as expected on the weekend content is published (see Jenner 2014, 11). Yet, as House of Cards and Orange is the New Black have shown, long-term social media buzz and mouth-to-mouth propaganda, in combination with the binge-model, the viewing numbers immediately after publication (particularly of new texts) may be less relevant for VOD than for television.

As Jason Jacobs points out, the success of the 'binge model' (whether in the format of DVD or VOD), has to do with the fact that new technologies allow for the viewing of texts without interruption or 'pollution' by adverts, thus avoiding what has historically been conceptualised as the televisual flow:

The difference between the VCR - the earliest domestic weapon against interruption and chronological authority of the broadcast schedule - and digital television technology seems to be that the various ways to own, time-shift or otherwise mine texts are promoted as the obvious and routinized ways to interact with the medium rather than viewing the schedule in real time. (2011, location 3125)

The serial form combined with technologies that give viewers the authority to decide when to watch what with the added benefit of avoiding interruptions by ads seems to be what drives binge-watching. The links the concept of binge-watching has with media forms that are associated with self-scheduling suggests that autonomous viewership is a key aspect of bingewatching. Thus, it is important to note that binge-watching is a concept intrinsically linked to autonomous scheduling and time-shifting technologies. 
In the case of VOD and DVD, no schedules are suggested, setting them apart from time-shifting technologies like VHS or DVR. DVD and VOD do not allow to record content and watch it at a more convenient time, but they never dictate a time (other than a release date) when content should be watched at all. As Derek Kompare argues:

Timeshifting, i.e., recording programs for later playback, destabilizes the relationship between advertiser, broadcaster, and viewer, separating the scheduled time from the viewing time. Accordingly, as advertisers and broadcasters fear, commercials are likely to be skipped on the eventual viewing of the recorded program. However, timeshifting alone is generally only a postponement of broadcast flow; once watched, it is likely that recorded programs are not watched again. $(2005,203)$

But DVD technology allows for a different kind of viewing experience:

...the introduction of DVD technology at the turn of the century provided a critical spark to the expansion of television on home video, due to several interrelated factors: the rapid, exponential growth of the DVD market, the unique properties and distinction of the technology itself, and the successful creation and exploitation of cult audiences. The culmination of these factors has been the season box set, the video object that successfully converted broadcast flow to published text, and finally crystallized television, and its repetition, into a tangible form. (ibid., 205)

Kompare terms this acquisitive repetition, meaning that the object is bought and consumed, presumably repeatedly. This idea that at least parts of television can be owned in the form of DVD box sets is part of a 'DVD effect'. When it comes to VOD it is important to differentiate between catch-up services like BBC iPlayer or, in its most basic form, Hulu and, on the other hand, the more developed HuluPlus, which offers more episodes of some series and original 
content, Netflix and Amazon Instant Video. Catch-up services usually only provide a limited amount of episodes and makes them available shortly after they air. Ad breaks are often included and close ties to the television schedule and the branding infrastructure of television channels are kept (see Jenner 2014, 3). Thus, these catch-up services are, essentially, timeshifting technologies. But VOD services like Netflix are closer to DVD, allowing for the consumption of ‘crystallised television’ or, in Jacobs’ terms (2011, location 3125), freed from the pollution of the flow of broadcast television.

To look specifically at Netflix, personalised recommendations or suggestions are offered instead of a broadcast schedule: these are based on previous viewing choices and ratings as well as responses to a (not mandatory) questionnaire. As Bethan Jones (2014) observes on her blog, recommendations can even be named after specific characters from Netflix original dramas, such as Piper Chapman from Orange is the New Black, thus playing to a viewer's (assumed) fandom. As journalist Alexis C. Madrigal outlines in an article for The Atlantic, these recommendations are the result of a careful system that rates attributes in films and viewing and rating behaviour of individual users:

They [Netflix employees] capture dozens of different movie attributes. They even rate the moral status of characters. When these tags are combined with millions of users viewing habits, they become Netflix's competitive advantage. The company's main goal as a business is to gain and retain subscribers. And the genres that it displays to people are a key part of that strategy. 'Members connect with these rows so well that we measure an increase in member retention by placing the most tailored rows higher on the page instead of lower,' the company revealed in a 2012 blog post [see http://techblog.netflix.com/2012/04/netflix-recommendations- 
beyond-5-stars.html]. The better Netflix shows that it knows you, the likelier you are to stick around (Madrigal 2014).

Yet, what results are only recommendations of content. It is entirely up to viewers when what is watched. Thus, viewing can be organised around personal schedules or mood. Scheduled television does not allow for this kind of viewer independence. On the other hand, as Glebatis Perks points out, the Netflix interface starts playing the next episode after only fifteen seconds before the closing credit sequence of the previous episode has finished. This interface seems to urge binging:

This insulated flow announces itself, making viewers take ownership of their experience, but its automaticity makes it difficult for viewers to escape the insulated flow. They may already envision themselves as moving through that fictive world. Instead of having to opt-in to a marathon, viewers are made to opt-out. (2015, location 456)

Though other VOD services urge binging to a much lesser extent than Netflix, it is important to bear this tension between viewer autonomy and interface in mind. But this also shows how central binge-watching is to VOD companies as publication model as well as suggested viewing protocol for this new medium.

\section{Quality TV as Bingeable Texts}

Another aspect of binge-watching is the text. This may seem curious considering its status as a specific viewing protocol, but the term seems to be linked to a certain kind of text that encourages this. Hills argues that the fact that a series is published on DVD seems to already suggest a certain cultural (and commercial) value: 
If DVD culture works, partly, on television to re-position many of its texts as symbolically bounded and isolatable 'objects' of value, then as a machinery of valorisation stressing the 'total system' of TV serials and series, it works to popularise 'close reading' and the artistic recontextualisation of some TV content. But this is seemingly true only in so far as these reading tactics (characteristic of fan and academic subcultures) can be made to fit with commercial strategies of branding and value-generation. DVD works to support academic 'close readings', and in turn these reading protocols—-wittingly or otherwise-are drawn into complicity with the commercial, valorising systems of TV broadcasters and rights-owners. (Hills 2007, 49)

In other words, not only are texts chosen to be published, but the viewing protocols (bingewatching) implied in the DVD form are accepted by rights-holders. It is worth mentioning that Hills discusses historical television published on DVD, but similar value judgements are being made by VOD providers. In line with this, bingeing is associated with so-called 'quality' or 'cult' texts like Breaking Bad or Mad Men, Firefly (Fox, 2002-3) or Supernatural. These are texts that have escaped the low-culture associations of television, in parts, it is argued here, through their 'binge-worthiness'.

This 'binge-worthiness' is, at least partially, owed to particularly complex narrative structures. Sharon Marie Ross points out that complex narrative structures are part of an invitation to viewers, though she argues herself that this kind of invitation is 'obscured':

By obscured, I mean to describe a style of invitation that is apparently careless, operating at a primarily aesthetic level; in other words, any invitation to participate resides primarily in the narrative structure and 
content of the show itself through a certain 'messiness' that demands viewer unravelling. (2008, 8-9, italics in the original)

Texts like The Wire (HBO, 2002-8) or Lost (ABC, 2004-10) with exceptionally complex narrative structures reward binge-watching and re-watching.

But 'bingeable’, 'quality’ texts are also often consciously constructed as aligning with middle class taste structures. For example, The Wire creator David Simon, television scholarship and journalistic criticism have compared the series to the literature of Charles Dickens (Klein 2009), Herman Melville (Simon himself in a talk at the Paley Centre, included in the Season 3 DVD extras) and Leo Tolstoy (Mittell 2011), to name just a few. Thus, this highly 'bingeable’ text with its extraordinarily complex narrative structure (see Rose 2008), is not constructed as low-brow television, but akin to high-brow literature. Another binge-worthy text, Mozart in the Jungle (Amazon, 2014- ) deals with the New York Symphony orchestra and features mostly classical music as its soundtrack, aligning it with middle class taste structures (see Bourdieu 2010, 264-80).

The cultural credence a bingeable text like The Wire or Mozart in the Jungle is invested with and the kind of viewer attention it demands points to another important aspect: 'quality' texts seek to appeal to the structures of taste of a middle-class 'quality demographics':

A quality demographic is young, affluent viewers, with money to spend, and with the cultural capital that translates into recognition by industry tastemakers with Emmys and other prestige awards. (Seiter and Wilson 2005, 140)

This aspect is particularly important for the subscription-based VOD services of Amazon or Netflix. After all, they rely on audiences who can afford to not only subscribe and continue 
their subscriptions, but also own the technology needed to consume it, such as computers, tablets or smartphones and a broadband internet connection. Furthermore, the original dramas, which feature cult stars like John Goodman or Malcolm McDowell or stars known from 'highculture’ film successes like Kevin Spacey, rely on the 'tastemakers' approval for social media buzz and mouth-to-mouth propaganda.

Hills describes three features as common to so-called cult texts: the author figure as a 'subjectwho-is-supposed-to-know', an endlessly deferred narrative, meaning that the text is marked by certain enigmas and the resolution of these is deferred over many seasons (and in some cases never occurs), and hyperdiegesis, meaning "a vast and detailed narrative space, only a fraction of which is ever directly seen or encountered within the text, but which nevertheless appears to operate according to principles of internal logic of extension” $(2002,137)$, such as the diegetic worlds of Firefly or The X-Files (Fox, 1993-2002). The endlessly deferred narrative may also explain why so many texts that were cancelled before central enigmas could be resolved, like Firefly, enjoy such an enthusiastic cult following. Discussing Twin Peaks (ABC, 1990-1), which knowingly poses a new enigma in its final episode, Hills argues:

This posing of a mystery even in the face of cancellation may help to explain the enduring presence of many cult shows. Sometimes the most endlessly deferred narrative of all is that which will never officially be answered or closed down, remaining open to multiple fan productions, speculations and recreations. (ibid., italics in the original)

Of course, it is difficult to pin down a label like 'cult', which is also determined by fan practices and secondary texts (see also Hills 2004, 510-1). These characteristics can be applied to contemporary 'quality' texts, as well. The 'quality' texts themselves are also complex narratives, fulfilling the criteria Hills sets out for cult texts with endlessly deferred narratives 
and the hyperdiegeses, as discussed below. The original dramas of Netflix are all on-going at the time of writing, but the notoriously ambiguous ending of The Sopranos (HBO, 1999-2007) sets a tone for the open nature of endings of contemporary 'quality' dramas: the ending of Six Feet Under (HBO, 2001-5) seems to fast-forward through hundreds of new stories and those of The Shield (FX, 2002-8) or Breaking Bad seem more like beginnings of different stories than endings. A major disparity between the two categories of 'cult' and 'quality' TV seems to be comparisons to 'high art', as The Wire's supposed likeness to literature. Yet, Twin Peaks, drawing comparisons to modernist art (see Creeber 2004, 48-56) and attracting a passionate fan-base even 25 years after it first aired easily fits in both categories. Thus, the categories of 'quality' and 'cult' need to be viewed as not always separate. Neither one is exclusively defined through text. Rather, they are discursively produced, fluid, flexible and often overlapping. Yet, it is important for this discussion that texts of both categories reward attentive, autonomously scheduled viewing and are invested with more cultural credence than most television.

Thus, binge-watching seems less associated with the low-brow medium of television, as Ramsay suggests, but the term binge seems to imply a conscious turning away from a medium that viewers sit down and watch whatever is scheduled for them. Instead, a binge implies a deliberate choice of watching serialised ‘quality' content. The 'shameful indulgence' seems less the viewing of a specific text, but not being able or willing to end the experience. Glebatis Perks' study into marathon viewing finds that viewers use the recognition of a series as 'quality’ to justify or alleviate guilt over binge-watching (2015, location 653). In other words, the concept of binge-watching is, as far as cultural connotations go, much closer to reading a 'page-turner' than the supposedly passive watching of 'whatever is on TV'. As Brunsdon argues, the verb binge, 
...with all its connotations of an uncontrollable, excessive consumption, ironically reconnects the prestige dramas, marketed as being superior to 'television', with the addiction metaphors that have always been used to characterize the consumption of television drama. $(2010,65)$

But binge-watching as a way to consume 'quality' texts on DVD and VOD seems to be used to describe a specific viewing protocol that differs from the 'old' way of watching TV. It may even function as a linguistic alternative to 'watching TV', relating to a different medium and a different kind of consumption. This is particularly likely as many of the texts cited on lists of 'bingeable' or 'binge-worthy' texts are still on-going, implying that viewers should bingewatch contemporary programmes rather than already finished ones like Six Feet Under or The Dick Van Dyke Show (CBS, 1961-6). ${ }^{2}$

\section{Fans, Non-Fans and Binge-Watching}

As argued above, a binge rewards attentive viewing, suggesting not only the viewing of an excessive amount of episodes, but also a somehow excessive audience-text relationship. In this, may be less the amounts of hours spent watching, but the intensity of the experience that is a deciding factor. After all, the kind of focus demanded by these 'quality' and 'cult' texts may not be necessary or wanted with other television formats. This audience-text closeness is a key factor of fandom. As Hills points out, discussing cult TV fandom:

Being a fan of cult TV doesn't mean just displaying subjective enthusiasm or a 'special devotion'. It also means, at the very least, being able to attempt to account for and defend one's fan passions; being able to analyse and critically appreciate one's favoured text; and attempting to ward off negative portrayals of fan cultures. $(2004,517)$ 
This implies a close audience-text relationship that enables viewers to interpret and think about a text. Arguing for an understanding of fandom less dominated by the high/low culture binary, Roberta Pearson describes an exchange with William Uricchio, in which he referred to her as having a 'fannish disposition':

He speculated that non-fans like himself engage in aesthetic reflection or are temporarily moved by cultural texts but that fans like me incorporate the cultural texts as part of their self-identity, often going on to build social networks on the basis of shared fandom. $(2007,101-2)$

In no way excluding fandom, the practice of binge-watching equally encourages non-fans to be 'temporarily moved’ by a text. Jonathan Gray defines non-fans as follows:

By non-fans, I mean those viewers or readers who do view or read a text, but not with any intense involvement. Non-fans likely have a few favourite programmes and are fans at other times [...] but spend the rest of their television time grazing, channel-surfing, viewing with halfinterest, tuning in and out, talking while watching and so on. $(2003,74)$

Gray’s definition is problematic for the concept of binge-watching. First of all, having been published in 2003 and relating back to Gray's earlier fan research, its definitions refer to a period just before binge-watching DVD box sets, let alone VOD, became a common practice. But Gray also does not capture the experience Pearson and Uricchio describe of being 'temporarily moved' by a text, but unwilling to participate in fan communities, adopt the fan label, or incorporate one's fandom into one's self-identity. Much of this may be due to the fact that the term non-fan necessarily includes those who are generally unaware of and uninterested in popular culture to those who regularly binge-watch DVDs and VOD, but are only ever ‘temporarily moved’ and reject fan labels. Gray conceptualises non-fans as much more passive than fans or anti-fans, but binge-watching necessarily involves deliberation and active viewing. 
Thus, in reference to the concept of binge-watching, it is the latter version of non-fan that is meant here. In this, they can be viewed as occupying an in-between space between fan and non-fan - at least in the sense Gray describes. The current media and social media environment strongly encourages fan-like behaviour and makes it easy to participate (binge-watching, tweeting, joining facebook groups) and there seems to be a need to locate those who engage in fan-like behaviour, but without adopting the fan label or participating in a community. To use Pearson’s language, binge-watching a series does not make it part of one’s self-identity.

Some of these non-fans might even participate in other fan-practices, such as buying ancillary materials like a t-shirt or a mug. But with the exception of Breaking Bad, little ancillary material is available for fans of 'quality' texts like The Wire or True Detective. None of this is to suggest that fan practices do not surround these quality texts: Breaking Bad has spawned a lot of ancillary material, ranging from mugs and T-shirts to action figures and fake blue meth sweets or bath salts. During its early seasons, Mad Men dolls were produced and the series was a common reference point for contemporary fashion. Fake twitter accounts were created (see Jenkins et al. 2013, 30) for characters and even the Xerox machine, and a range of Tumblr pages are dedicated to all of these 'quality' and simultaneously 'cult' texts. But what needs to be emphasised is that the practice of binge-watching, though rooted in fandom, is not exclusive to fan practices. As opposed to a non-fan/fan binary, VOD encourages fan-like behaviour in non-fans. In other words, the binge, as a viewing practice mostly associated with fans, has been moved to be a practice associated with watching 'quality' and cult TV. This blurred line between non-fans and fans, 'quality' and 'cult', 'low-culture' TV and 'high-culture' serialised drama is exploited by VOD through the concept of the binge.

Perhaps binge-watching can be viewed as a part of what Schäfer describes as explicit and implicit participation. Where explicit participation is "driven by motivation” (2011, 51), 
implicit participation is "channelled by design, by means of easy-to-use interfaces, and the automation of user activity processes” (ibid.). Though Schäfer states that social media and the deliberation implied in posting or creating content does not necessarily need to be implicit, the 'openness' of twitter communications, which can be statements directed at nobody in particular, or the ease with which Tumblr images created by others can be shared, points to implicit activity.

Participation can in fact also be formalised as a default design feature that unfolds as an implicit activity. This form of implicit participation is intrinsically related to the Internet and the World Wide Web. (ibid.,105)

Examples of this could be social media, but also the sharing of a private dropbox folder containing content. Some sort of participation is inherent in the nature of Web 2.0, its systems of file sharing or social media. Thus, it is hardly surprising that non-fans engage in practices such as tweeting and detailed analysis of a text. The consumption of serialised content on VOD is not participation in itself, though commenting on content on social media is. Binge-watching does not count as implicit participation. Yet, it enables this kind of participation and audiencetext closeness. Binge-watching also enables viewers to participate explicitly and implicitly in social phenomena by allowing viewers to catch up with much-discussed dramas like Breaking Bad and participate in textual analysis. Binge-watching and the technology that supports it, thus, needs to be viewed as an important aspect of how fan practices, participation and textual production, are moved into a 'mainstream' culture.

This blurring of boundaries may be linked to the fact that, as Henry Jenkins points out, the once marginalised figure of the fan has been accepted into the 'mainstream' and fan practices are being reframed and redefined (2002). DVD culture supports this: via the gateway of 'quality' 
TV non-fans have been encouraged to participate in fan, or at least fan-like, behaviour. As Ernest Mathijs and Jamie Sexton argue, discussing cult film:

The increasing proliferation of digital technologies within everyday life is further blurring the boundaries between cult and mainstream. [...] The internet massively increases the (virtual) public presence of film fans, many of whom leave online traces of their love for films via discussion forums, blogs, web sites, and social networking sites, to name some prominent examples. $(2011,64)$

Moving away from the object of the DVD, VOD has removed some material that might particularly appeal to fans, such as blooper reels, commentary or making-offs. VOD also does not provide the prized object of the DVD to display on a shelf. VOD 'slims down' the medium of the DVD to offer a text without the pollution of the television flow, but also without features that fans may value highly. Thus, it offers an opportunity to non-fans to adopt the viewing protocol without adopting other fan behaviour.

\section{Conclusion}

As outlined in this article, binge-watching may be best understood as an intersection of discourses of fandom filtering into the 'mainstream', 'quality' and 'cult' TV, technologies and industry practices. With the lines between fans and non-fans increasingly blurred, the practice of binge-watching, despite its etymological links to unhealthy behaviour, signifies a socially legitimised excess, the luxury of time and 'quality' television combined in implicit fan activity. As such, it may imply the agency commonly associated with fans, but conceptualises this as inherent to VOD. The VOD industry takes advantage of the autonomy and agency implied in binge-watching by using publication models and interfaces that encourage bingeing, attempts to predict and manipulate viewer behaviour and marketing (original) serialised drama over 
other content. But binge-watching is also a way to describe 'watching VOD', understanding it as decidedly different from 'watching TV', one being autonomously scheduled and active the other programmed by broadcasting institutions, implying a potentially passive viewership. If viewed this way, then the line between fans and non-fans lies mostly in the self-identification. After all, binge-watching 'quality' and 'cult' texts becomes a 'mainstream' activity with VOD and bingeing enables detailed textual analysis. Therefore, the willing adoption of the fan label and participation in a community may be the most significant distinction between fans and nonfans who watch, or binge, VOD. The VOD industry relies on the adoption of such behaviour to market itself, giving itself an air of following audience desires by drawing on experiences from its own past as DVD rental stores and its own technological data, but also urging bingeing through interfaces. Thus, the binge as concept is defined by these inextricably linked discourses. Other discourses, such as technological developments, algorithmic programming and its interactions with users, contemporary capitalism and marketing strategies, or consumerist implications of the mainstreaming of fandom also play into the construction of the concept of the binge, but reach beyond the scope of this article.

\footnotetext{
${ }^{1}$ Since the late 1990s, HBO has come to signify 'quality' television, building its brand around setting a standard for 'quality' serialised drama (see, for example, Johnson 2012, 32)

${ }^{2}$ There are a number of exceptions from Twin Peaks to The Sopranos, but the vast majority is on-going.
} 


\section{Bibliography}

Bourdieu, P. (2010 (1984)). Distinction: a Social Critique of the Judgement of Taste. London: Routledge.

Brunsdon, Charlotte (2010) "Bingeing on Box-Sets: The National and the Digital in Television Crime Drama." In Relocating Television: Television in the Digital Context, edited by Jostein Gripsrud. London: Routledge. 61-75

Carr, D. (2013). With 'Alpha House,’ Amazon Makes Bid for Living Room Screens and Beyond. In: The New York Times. Online:

http://www.nytimes.com/2013/11/04/business/media/with-alpha-house-amazonmakes-bid-for-living-room.html?smid=twnytmedia\&seid=auto\&_r=2\&pagewanted=all\&, Accessed on: 03.01.2015

Creeber, G. (2004). Serial Television: Big Drama on the Small Screen. London: BFI.

Dockterman, E. (2013). Amazon Wants You to Actually Leave Your House Instead of BingeWatching Its Shows, Time. Online: http://business.time.com/2013/11/05/amazonwants-you-to-actually-leave-your-house-instead-of-binge-watching-its-shows/. Accessed on: 05.11.2014

Feeney, N. (2014). When, Exactly, Does Watching a Lot of Netflix Become a 'Binge'?, The Atlantic. Online: http://www.theatlantic.com/entertainment/archive/2014/02/whenexactly-does-watching-a-lot-of-netflix-become-a-binge/283844/. Accessed on: 03.01.2015

Glebatis Perks, L. (2015). Media Marathoning. Immersions in Morality. London: Lexington Books.

Gray, J. (2003) New Audiences, New Textualities. Anti-fans and non-fans. In: International Journal of Cultural Studies. 6 (1). 64-81.

Hills, M. (2002). Fan Cultures. London: Routledge.

Hills, M. (2004). Defining Cult TV. In R. C. Allen \& A. Hill (Eds.), The Television Studies Reader. London and New York: Routledge. 509-23

Hills, M. (2007). From the Box in the Corner to the Box Set on the Shelf. New Review of Film and Television Studies, 5(1), 41-60.

Hills, M. (2013). Fiske’s ‘Textual Productivity’ and Digital Fandom: Web 2.0 Democratization Versus Fan Distinction? Participations, 10(1), 130-153.

Jacobs, J. (2011). Television, Interrupted: Pollution or Aesthetic? In J. Bennett \& N. Strange (Eds.), Console-ing Passions: Television as Digital Media. Durham and London: Duke University Press, Kindle. Location 3065-401

Jenkins, H. (2002). Interactive Audiences? The 'Collective Intelligence' of Media Fans. Online: http://web.mit.edu/21fms/People/henry3/collective\%20intelligence.html. Accessed on: 03.01.2015

Jenkins, H., Ford, S., \& Green, J. (2013). Spreadable Media: Creating Value and Meaning in a Networked Culture. New York ; London: New York University Press.

Jenner, M. (2014). Is This TVIV? On Netflix, TV III and Binge-Watching. New Media \& Society, OnlineFirst, 1-18.

Johnson, C. (2012). Branding Television. Abingdon, Oxon ; New York: Routledge.

Jones, B. (2014). Netflix Categories as Paratexts? Online: https://bethanvjones.wordpress.com/2014/11/17/netflix-categories-as-paratexts/. Accessed on: 03.01.2015

Klein, A. A. (2009). "The Dickensian Aspect”: Melodrama, Viewer Engagement, and the Socially Conscious Text. In C. W. Marshall \& T. Potter (Eds.), The Wire: Urban Decay and American Television. New York: Continuum. 177-89

Kompare, D. (2005). Rerun Nation: How Repeats Invented American Television. New York: 
Routledge.

Lotz, A. D. (2014). The Television will be Revolutionized (Second edition. ed.). New York and London: New York University Press, Kindle.

Madrigal, A. C. (2014). How Netflix Reverse Engineered Hollywood. In: The Atlantic. Online: http://www.theatlantic.com/technology/archive/2014/01/how-netflix-reverseengineered-hollywood/282679/. Accessed on: 28.08.2014

MarketCast (2013) "Marketcast Releases New Study, "Marathon TV: How Binge-Viewing Is Changing the Way We Watch”. Online: http://www.mcast.com/bingestudy/. Accessed on: 09.01.2015

Mathijs, E., \& Sexton, J. (2011). Cult Cinema: An Introduction. Oxford: Wiley-Blackwell.

Mittell, J. (2011). All in the Game: The Wire, Serial Storytelling, and Procedural Logic. Electronic Book Review. In: electronicbookreview. Online: http://www.electronicbookreview.com/thread/firstperson/serial. Accessed on: 03.01 .2015

Netflix Press Releases (2013). Netflix Declares Binge Watching is the New Normal. Study Finds $73 \%$ of TV Streamers Feel Good About It. Online: https://pr.netflix.com/WebClient/getNewsSummary.do?newsId=496. Accessed on: 03.01.2015

Newman, M. Z. (2014). Video Revolutions: on the History of a Medium: Columbia University Press, Kindle.

Pearson, R. (2007). Bachies, Bardies, Trekkies, and Sherlockians. In J. Gray, C. Sandvoss \& C. L. Harrington (Eds.), Fandom: Identities and Communities in a Mediated World. New York ; London: New York University Press. 98-109

Prudom, L. (2014, 12.07.2014). Amazon's 'Transparent' Season 1 to Debut Late September, 'Bosch' Premiering Early 2015. In: Variety. Online:

http://variety.com/2014/digital/news/amazon-transparent-full-season-premiere-bosch2015-1201261698/. Accessed on: 03.01.2015

Ramsay, D. (2013). Confessions of a Binge Watcher. In: CST Online. Online: http://cstonline.tv/confessions-of-a-binge-watcher. Accessed on: 03.01.2015

Rose, B. G. 2008. The Wire. In: EDGERTON, G. R. \& JONES, J. P. (eds.) The Essential HBO Reader. Lexington: The University Press of Kentucky. 82-91.

Ross, Sharon Marie (2008) Beyond the Box: Television and the Internet. Malden, Oxford: Blackwell.

Schäfer, M. T. (2011). Bastard Culture!: How User Participation Transforms Cultural Production. Amsterdam: Amsterdam University Press.

Seiter, E., \& Wilson, M. J. (2005). Soap Opera Survival Tactics. In G. R. Edgerton \& B. G. Rose (Eds.), Thinking Outside the Box. A Contemporary Television Genre Reader. Kentucky: The University Press of Kentucky. 136-55

\section{$\underline{\text { Television and VOD }}$}

30 Rock (2006-13), USA: NBC

Alpha House (2013- ), USA: Amazon

Arrested Development (2003- 2013), USA: Fox, Netflix 
Breaking Bad (2008-13), USA: AMC

Deadbeat (2014- ), USA: Hulu

Farmed and Dangerous (2013- ), USA: Hulu

Firefly (2002-3), USA: Fox

Game of Thrones (2011- ), USA: HBO

Girls (2012- ), USA: HBO

Hemlock Grove (2013- ), USA: Netflix

House of Cards (2013- ), USA: Netflix

Lilyhammer (2012- ), USA: Netflix

Lost (2004-10), USA: ABC

Mad Men (2007- ), USA: AMC

Mozart in the Jungle (2014- ), USA: Amazon

New Girl (2011- ), USA: Fox

Orange is the New Black (2013- ), USA: Netflix

Peep Show (2003- ), UK: Channel 4

Revenge (2011- ), USA: ABC

Scandal (2012- ), USA: ABC

Sherlock (2010- ), UK: BBC

Six Feet Under (2001-5), USA: HBO

Supernatural (2005- ), USA: CW

The Dick Van Dyke Show (1961-6), USA: CBS

The Good Wife (2009- ), USA: CBS 
The Newsroom (2012- ), USA: HBO

The Shield (2002-8), USA: FX

The Sopranos (1999-2007), USA: HBO

The Wire (2002-8), USA: HBO

The X-Files (1993-2002), USA: Fox

Transparent (2014- ), USA: Amazon

True Detective (2014- ), USA: HBO

Twin Peaks (1990-1), USA: ABC 